\title{
An Impact Study of the Implementation of a Materials Science and Engineering Module at the Fifth Grade Level
}

Souheil Zekri ${ }^{1}$, LaNetra Clayton ${ }^{2}$, Emily Ferguson ${ }^{3}$, Geoffrey Okogbaa ${ }^{4}$, Ashok Kumar ${ }^{1}$, Tapas Das $^{4}$, Grisselle Centeno ${ }^{4}$, and Louis Martin-Vega ${ }^{4}$

${ }^{1}$ Mechanical Engineering, University of South Florida, Tampa, Florida 33620

${ }^{2}$ Chemistry, University of South Florida, Tampa, Florida 33620

${ }^{3}$ Biology, University of South Florida, Tampa, Florida 33620

${ }^{4}$ Industrial Engineering, University of South Florida, Tampa, Florida 33620

\section{ABSTRACT}

An impact study of the implementation of a newly developed Materials Science and Engineering Module was conducted as part of a National Science Foundation funded GK-12 project at the University of South Florida. The objective of GK-12 STARS (Students, Teachers and Resources in the Sciences) program is to foster systemic change in elementary by enriching math and science curricula and encouraging long-term professional development for teachers in the K-5 band. The program also aims to decrease the current educational gap in science and math curricula prevalent among certain schools within the same school district, which is reflected in the outcome of the Florida Comprehensive Assessment Test (FCAT). The module was developed for the purpose of enhancing existing textbook driven science instruction and creating a fundamentally sound scientific exposure in elementary school students. As part of this activity, students from three different schools (one private, one suburban, and one urban) were introduced to basic concepts in materials science and engineering through hands-on experiments, presentations, and field trips to the university's material research related laboratories (i.e. polymer chemistry, microelectronics, nanotechnology, geotechnics, corrosion, etc.) The developed module offered information ranging from basic definitions to newly discovered cutting edge phenomenon in the field of nanotechnology. Subsequently, pre and post test instruments were administered to assess student performance. Results from the pretest showed that students from all participating schools performed within the standard deviation. The post assessment test showed that the experimental group had twice as many correct answers, as the control group from each school.

\section{INTRODUCTION}

Developments in advanced technologies, such as microelectronics and nanotechnology, have rapidly increased during the second part of the twentieth century. The impact of these advances has tremendously affected everyday life, especially in developed countries. As a result of such advances, certain adjustments to the current GK-12 science and mathematics curriculum must take place in order to prepare these future generation of engineers and scientists for the forthcoming challenges of the new age materials in increasingly high-tech and global marketplace. Recent studies across the United States have demonstrated that students' achievement in science and mathematics lags behind that of students from other developed countries in Europe and Japan, and has not improved significantly over time [1,2]. Moreover, research indicates that science education is a concern for everyone from business leaders to scientists to educators [3]. 
As a result, the National Science Foundation (NSF) has developed a program that provides fellowships and training in educational pedagogy that allow graduate and advanced undergraduate students in science, technology, engineering, and mathematics to serve as knowledgeable resources to K-12 educators [4,5]. The University of South Florida (USF), Tampa, Florida, was awarded the GK-12 grant in 2001. The USF/NSF STARS program has a target population in the Hillsborough County, FL, USA school district. A strong partnership between USF and five area elementary schools in Hillsborough County has been established for this project. One of the goals of the USF/NSF STARS program is to infuse engineering and science principles in the curriculum through innovative edge modules that enhance the science instruction already in place, while at the same time maintaining the required competencies set forth in the Sunshine State Standards (SSS).

The state of Florida standards for science is divided into eight topics or strands, which provide introductory material to basic scientific principles. One of the topics, the Nature of Matter, is the foundation of the Materials Science and Nanotechnology Module. In order to measure the effectiveness of the standards taught in the classroom the state implemented the Florida Comprehensive Assessment Test (FCAT). In recent years, the science component of the SSS has been assessed through the FCAT. Although the results of the science FCAT component do not presently factor into determining a school's grade under the State of Florida's School Grading System [6], they are expected to count towards a school's overall grade in the near future. Thus, another goal of the USF/NSF STARS program is to design a series of modules that serve as prototypes for the FCAT assessment in science.

This paper will discuss the development, format, and implementation of one of the USF/NSF advanced modules for fifth grade science curriculum, Materials Science and Engineering. The actual implementation experience in the classroom as well as issues related to the assessment will be discussed.

\section{MODULE DEVELOPMENT AND LAYOUT}

The Materials Science and Engineering Module was designed to infuse advanced science concepts into elementary pedagogy in order to instruct $3^{\text {rd }}, 4^{\text {th }}$, and $5^{\text {th }}$ graders in the field. The goal of the module was to provide ample background for the teacher and concrete understanding for the students. The module consists of an extended background, pretest, four lessons and a posttest. The four lessons were entitled: (i) The wonders of a small world; (ii) The Edible Microchip; (iii) Concreation; and (iv) Mimicry. The main focus of these lessons was to incorporate fundamental concepts in atomic theory, nanoscience, and certain aspects of materials science and physics. These lessons were designed in order to provide the building blocks toward a clear understanding of nanotechnology at the fifth grade level.

The time required for the full implementation of the enhanced module, was one hour and fifteen minutes (this included teaching time and excluding activity preparation, question and answer, and review) for six consecutive days. The pretest questions were taken from the county adopted textbook [7]. These questions reflected the required information, according the Florida Sunshine State Standards that fourth graders should have learned while being taught Nature of Matter. The background was designed to provide teachers with the necessary information for them to understand basic concepts and vocabulary related to materials science. Concepts such as materials microstructure, composition, synthesis and processing were discussed. Examples of the relationship between functional use of certain materials and their corresponding properties 
were also introduced. The posttest consisted of questions directly related to the Materials Science and Engineering Module along with other questions related to the nature of matter module [8].

The first lesson, wonders of a small world, was an introductory lesson that discussed basic materials science concepts such as the classification of materials, nature of matter and atomic theory. The history of materials and the periodic table were also introduced as well as the concept of the nanometer in relation to atoms and molecules. Vocabulary such as nanometer, nanotechnology and their applications were introduced. Illustrations such as a magnified picture of the human hair and a distance of 10 nanometer next to its width were included in the first lesson. Two activities were performed during this lesson; the first activity consisted of constructing a water molecule using gum drops and toothpicks. The second activity involved the observation of gas evolution through the bubbling of hydrogen in a water electrolysis activity using a 12 volt battery and aluminum wires as electrodes. Lesson 2, Edible Microchip, continued with molecules forming polymer chains. The lesson further explored the use of polymers for microelectronic applications such as computer parts. Nanoparticles (specifically carbon nanotubes) were introduced for their potential ability to enhance the thermal conductivity of the polymer matrix used in coating the circuit board in computers. The third lesson, Concreation, introduced concepts such as composite materials, ratios, mixtures, and the force (in Newton) needed to break a non-reinforced and reinforced concrete block. Forces were determined following a bending test that was conducted on each specimen. Finally, lesson 4, biomimetics, emphasized how materials scientist and engineers mimic nature to advance technology. Students in this lesson were provided with a worksheet containing original cartoons depicting aspects of nature working collaboratively to solve a problem. For example, bees in a hive working to protect honey and the immune system working to fight off disease. At the end of the lesson, students were asked to develop a cartoon showing how a nanodevice would fight cancer inside the human body. Further information about these lessons is provided in [8].

\section{IMPLEMTATION AND EVALUATION}

The participating schools in the enhanced module implementation included a suburban school graded as an "A" school, an urban school which has not been graded in several years, and a private school that is not evaluated by the State grading system. The overall goals in the implementation of this enhanced module were to increase student awareness of the field of materials science and nanotechnology and to bridge the gap in science between the different schools the district.

The teachers participating in the GK - 12 STARS program in collaboration with the Fellows determined a schedule for teaching in their classrooms. Due to FCAT testing, some teachers were unable to provide adequate time for the enhanced module. The urban and the private school were more accommodating to a consistent, consecutive presentation of the lessons. The private school provided from one hour and twenty minutes to two hours for three days. The urban school allowed one hour and fifteen minutes for five sessions. However, the suburban school restricted the time the Fellow had to present the module effectively. In the suburban school the teacher provided forty-five minute sessions for four days. During the forty-five minutes, the presentation was extremely rushed. On some occasions, prearranged times were affected by the majority of students missing class for chorus or field trips that were not foreseen. Furthermore, three week 
delay for FCAT preparation and testing occurred in the middle of the Concreation lesson. This interruption posed a problem with the outcome of the lesson.

The sample population for the urban and suburban students consisted of accelerated gifted and advanced students. The private school does not separate students based on their achievement level. However, all students are admitted to the school after passing an aptitude test. The sample size for the urban school was eleven students, the suburban had twenty students, and the private had nineteen students. It is also interesting to note that the students from the urban school were all members of a previously established science club by the STARS Fellows. These children were also in mainstreamed classrooms prior to being introduced to the Materials Science and Engineering Module. In this mainstream classroom, the Nature of Matter Standards from the county adopted textbook in concert with the sunshine state standards were already taught by the teacher with assistance from a STARS Fellow.

Each student was provided with a worksheet for each lesson. Different lessons had different worksheets depending on the activities involved. The worksheet allowed students to draw or write important concepts addressed during the lesson. These worksheets were collected at the end of each lesson to check on their progress relative to their ability to take notes and comprehend the information presented. From these worksheets, the next session review was better facilitated to address concepts that were not clearly defined in their worksheets. These worksheets also served as a review guide prior to administering the posttest.

\section{RESULTS}

Results were obtained from the administration of a pretest and a posttest given to two groups; an experimental group, and a control group from each participating school. The pretest was administered to acquire some information regarding the fifth grade student's knowledge about nature of matter and the pre-existing material science related information up to the fourth grade level. The posttest, on the other hand, was designed to reflect the acquired knowledge of the experimental group after teaching the enhance materials science module.

Figure 1 shows the experimental and control group results in the three participating schools. The pretest shows that out of 12 questions, students from all schools answered anywhere between 4.5 and 6.5 correct answers. This range is well within the standard deviation which averaged 2.2.
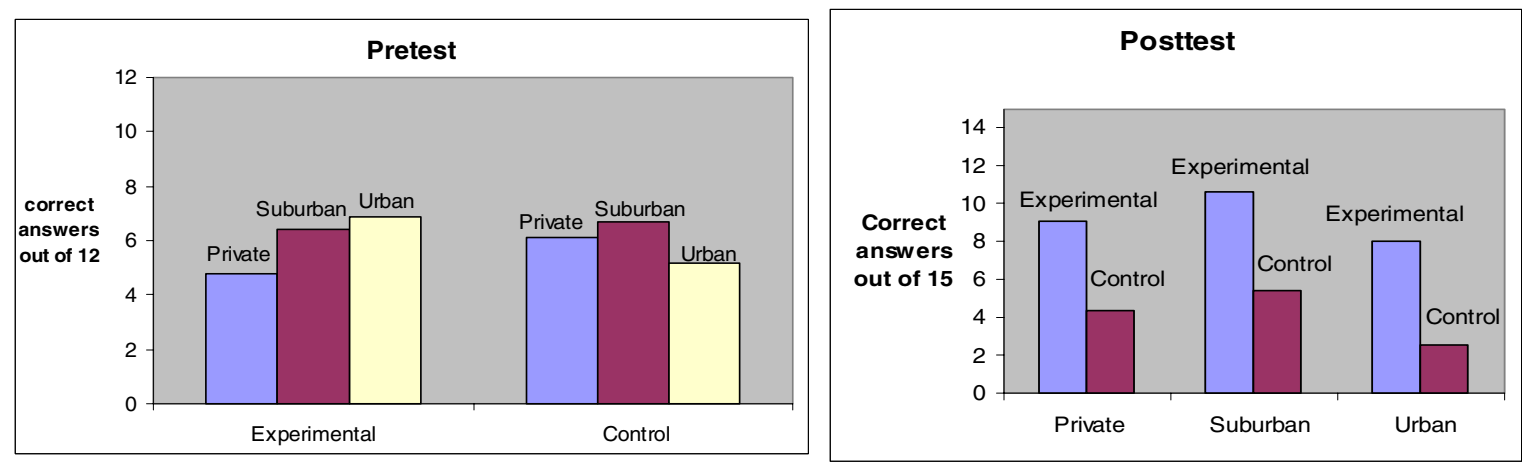

Figure 1: Plots showing average correct answers for experimental and control groups in each participating school. 
The posttest included questions directly related to the Materials Science and Engineering Module along with other questions related to the nature of matter module. The purpose of the posttest was to assess how much of the provided information was understood and assimilated by the experimental groups. Also, the authors were interested in seeing how much of the provided information is available to the control groups either in the classroom or outside. The posttest results show that the experimental group had about twice as many correct answers on average when compared to the control group throughout the three schools. The posttest results highlight the importance of infusing the materials science and engineering module content into the schools science curriculum to provide further understanding of basic materials science concepts.

More specific data were gathered based on the posttest questions. Two questions related to materials classification were included in the posttest. Figure 2 shows that the experimental groups from all participating schools had more correct answers than control groups. This result clearly shows that material classification is not included in both the public and private science curriculum.
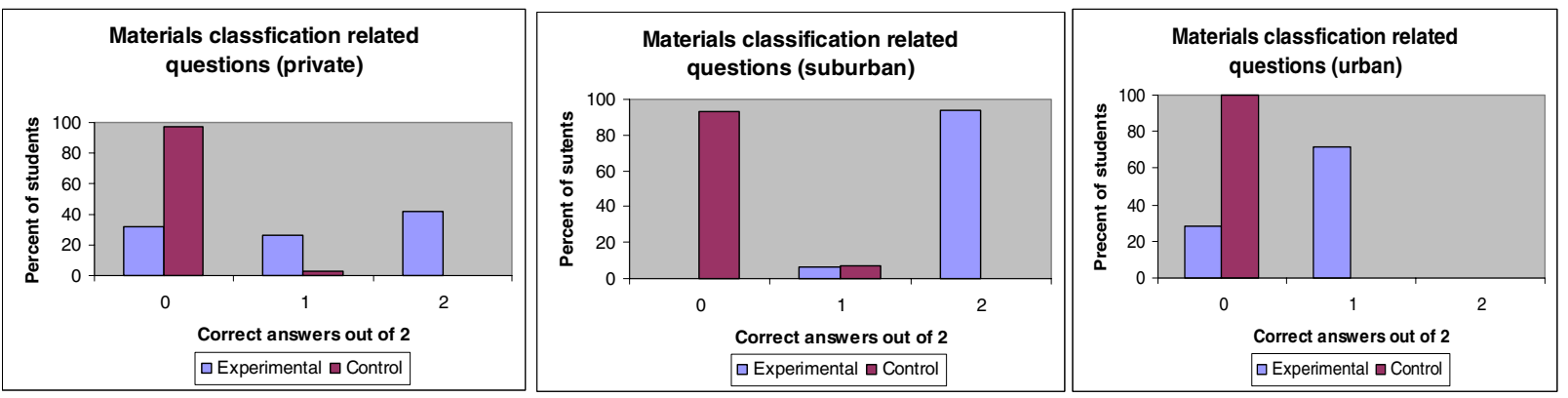

Figure 2: Plot showing the percent of students answering 0,1 , and 2 correctly out of 2 possible material classification related questions.

Materials properties was one of the primary focus points included in the designed module. Three of the questions included in the posttest assessed students' knowledge of common materials properties such brittleness, ductility, and capacity to conduct heat and electricity. Figure 3 shows that about twice as many students from experimental groups in all schools had two or three correct answers when compared to students from the respective control groups.

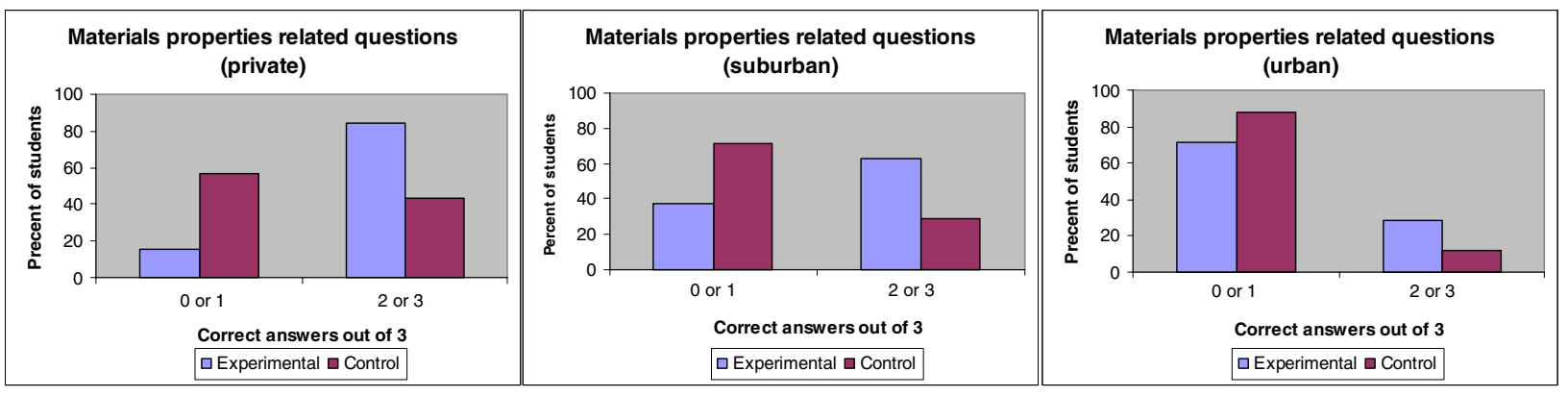

Figure 3: Plot showing the percent of students answering 0 or 1 , and 2 or 3 correct answers out of 3 possible material properties related questions. 


\section{CONCLUSION}

This paper presented an impact study of teaching a Materials Science and Engineering Module to fifth grade student from a private, suburban, and an urban school. Participating students from those schools developed a better understanding of basic materials science concepts and vocabulary. Furthermore, the students learned about the relationship among many common materials and their respective physical and chemical properties. The developed module also improved students' understanding of materials science related information already included in their curriculum. Finally, teachers from participating schools became more familiar with materials science concepts and research. This ultimately makes them more comfortable in addressing and incorporating materials science curriculum with increased effectiveness.

\section{ACKNOWLEDGMENT}

This work was supported by NSF GK-12 Fellowship grant \# DGE 0139348. The authors would also like to acknowledge Mrs. Brenda Hill and Mrs. Kattie Lattimore for the continuing support throughout the implementation of the Materials Science and Engineering Module.

\section{REFERENCES}

[1] W.H. Schmidt, C. McKnight, L. Cogan, P. Jakwerth, and R. Houang, Facing the Consequences: Using TIMSS for a Closer Look at U.S. Mathematics and Science Education, Boston, MA: Kuwer Academic Publishers (1999).

[2] J.R. Campbell, K. Voekl, and P. Donahue, NAEP 1996 Trends in Academic Progress, Washington, DC: National Center for Educational Statistics, NCES 97-986 (1997).

[3] Rutherford, F. J., and Ahlgren, A. Science for all Americans, New York: Oxford University Press, 1990

[4] G. Centeno, L. Clayton, L.D. Otero, S. Zekri, Paper accepted to Frontiers in Education (FIE) conference proceeding, Spring 2004.

[5] http://www.ehr.nsf.gov/dge/programs/gk12 (2004).

[6] http://www.firn.edu/doe/sas/fcat/fcat_menu.htm. (2004)

[7] M.S. Frank, et al, The Nature of Matter, Harcourt Science (fourth grade), Harcourt School Publishers (2000), p. E28-E29.

[8] http://stars.eng.usf.edu/ (2004). 